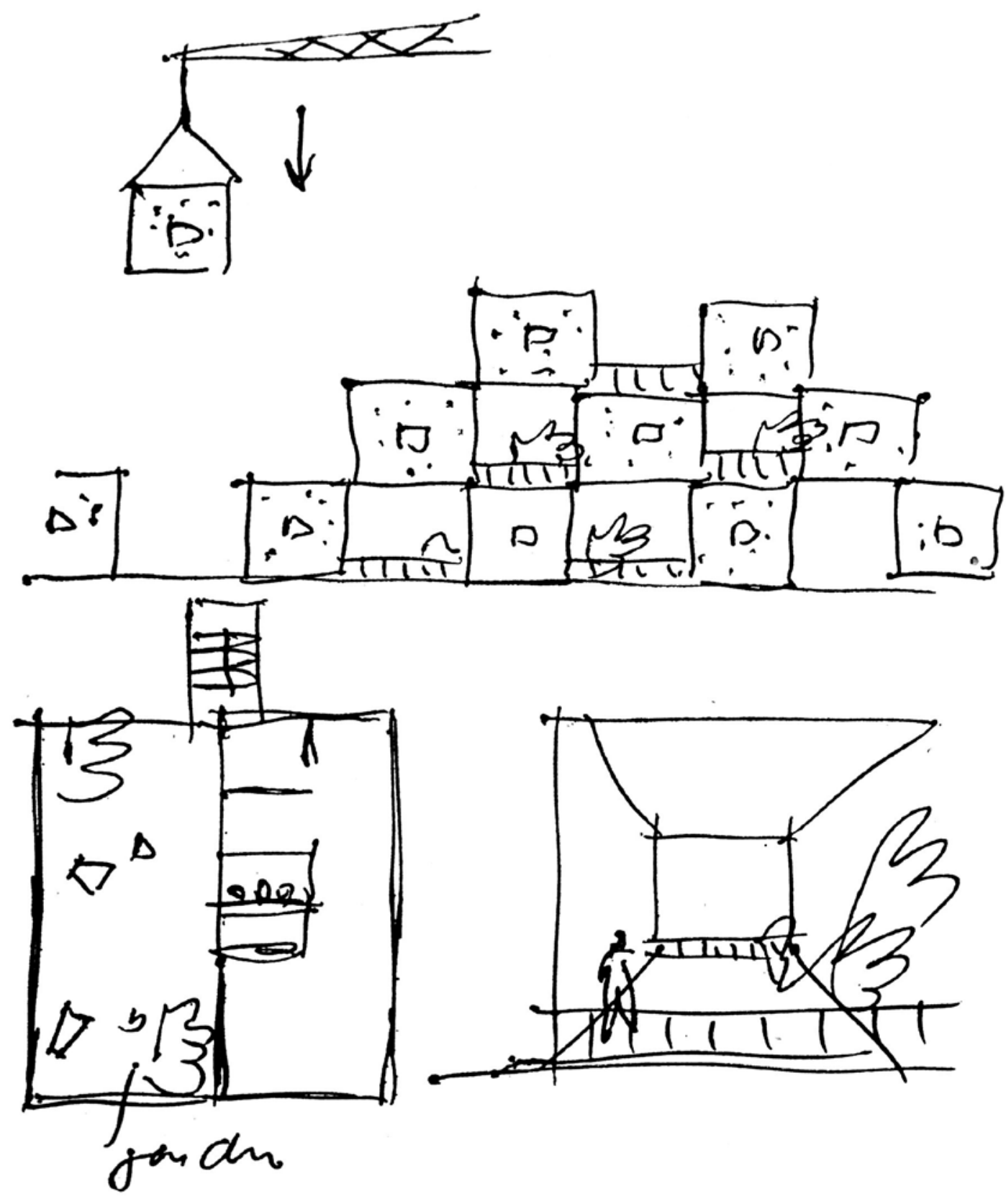



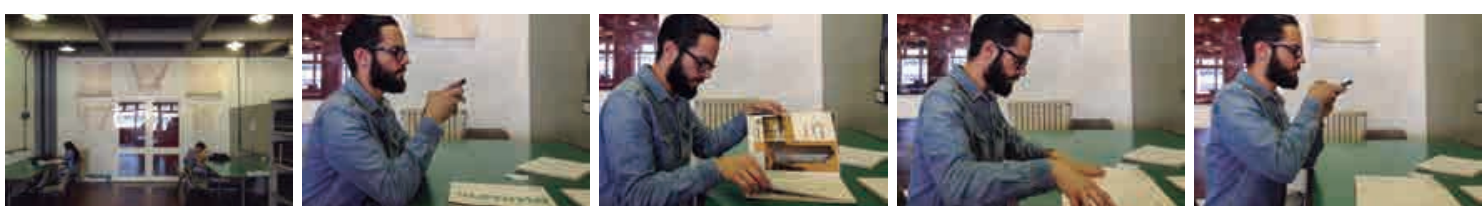

Secuencia: Pesquisa en hemeroteca de FADU y SCA en Buenos Aires

Fotos: Karine Vargas Soares

\title{
ESTRATEGIAS DE DEFENSA: TRES TEMAS RECURRENTES EN LOS TEXTOS DE NIEMEYER EN LA REVISTA MÓDULO'
}

\author{
DEFENSE STRATEGIES: THREE RECURRENT THEMES IN NIEMEYER'S TEXTS PU- \\ BLISHED IN THE MAGAZINE MÓDULO'
}

\author{
Mario Guidoux Gonzaga²
}

RESUMEN

Esta investigación trata sobre los textos publicados por Oscar Niemeyer en Módulo, una revista editada por el mismo arquitecto que circuló entre 1955 y 1989. La lectura de estos textos reveló tres temas recurrentes: el primero, presente incluso en la primera edición, trata de las respuestas a la crítica internacional; el segundo, que apareció por vez inicial en 1955 pero tuvo mayor notoriedad a partir de 1975, revela a un Niemeyer preocupado con el legado que su obra podía dejar para futuras generaciones de arquitectos; y el último, desarrollado en la última década de la revista, muestra un cambio en el discurso, en la medida en que adopta un tono menos didáctico en la explicación de sus proyectos e intenta destacar la relevancia de su figura, aun en los nuevos contextos. El análisis de estos documentos y la identificación con dichos temas evidencian las inquietudes del arquitecto sobre su práctica profesional y el uso de la revista para defenderlas.

Palabras clave: revistas, arquitectura moderna, siglo xx, historiografía, críticas.

\section{ABSTRACT}

This research deals with the texts published by Oscar Niemeyer in Módulo, a magazine edited by the architect himself, which was in circulation between 1955 and 1989. The reading of these texts revealed three recurrent themes: the first, present even in the first issue, has to do with the response to international criticism; the second, which initially appeared during the magazine's first year but gained greater notoriety after 1975, reveals a Niemeyer concerned with the legacy his work could leave for future generations of architects; and the last, evident in the last decade of the magazine, shows a change in discourse, which takes on a less didactic tone when explaining his projects and attempts to highlight his relevance, even in new contexts. The analysis of these documents and the identification of said themes demonstrate Niemeyer's concerns regarding his professional life and how he used the magazine to defend his work.

Keywords: magazines, modern architecture, 20th century, historiography, criticism.

Artículo recibido el 30 de agosto de 2016 y aceptado el 6 de diciembre de 2016 DOI: https://doi.org/10.22320/07196466.2016.34.050.06

[1] Este trabajo está basado en los resultados de la investigación A Revista Como Curadoria: Brasil e Argentina através das revistas Summa e Módulo. PROPAR - UFRGS, defendida por el autor en 2016 en el programa de Magister de la Universidade Federal do Rio Grande do Sul, Brasil.

[2] Programa de Pesquisa e Pós-Graduação em Arquitetura, Universidade Federal do Rio Grande do Sul, Porto Alegre, Brasil. Email: guidoux.gonzaga@gmail.com 
Módulo fue una revista de arquitectura y artes publicada en Río de Janeiro entre 1955 y 1989 bajo la dirección de Oscar Niemeyer. La publicación surgió en una época en que la arquitectura moderna brasileña, marcada por la obra del citado Niemeyer, "era el objeto preferencial de las críticas internacionales explícitas y nacionales veladas" (Zein, 2012). Aunque nunca haya sido declarado por sus creadores, el surgimiento de la revista puede ser entendido como una respuesta del arquitecto a las críticas. La revista fue, en efecto, una plataforma en la que pudo publicar su obra de la manera más conveniente.

En 1953, Habitat, revista de arquitectura de la pareja Lina Bo e Pietro Bardi, re-publicó la controvertida entrevista concedida por Max Bill a Manchete -una publicación de variedades muy popular en Brasil. El reportaje venía "acompañado de una nota en la cual los editores [condenaban] a los arquitectos de renombre que se habían rebelado contra las críticas de Bill" (Cabral, 2011:58). Fabiana Stuchi (2007) nota al respecto que en este reportaje destaca la "importancia de la crítica para la madurez de la producción brasilera", como una forma de evitar que la arquitectura moderna del Brasil acabase cayendo en la artimaña del academicismo. Este riesgo ya había sido alertado por Bruno Zevi en Historia de la Arquitectura Moderna, publicado originalmente en 1950. Según Carlos Eduardo Comas, las críticas de Max Bill publicadas en Habitat se sumaban tanto a Zevi, en la reprobación de un academicismo que "repetía sin justificativa convincente la forma libre, forma orgánica o planta libre, las fachadas de vidrio, los brise-soleil y los pilotis popularizados por Le Corbusier" (2011:43), como a las reseñas de la exposición Brazil Builds -realizada en 1943 en el MoMa - en lo relativo a responsabilidad social. Sobre este último aspecto, Elizabeth Wilder, editora de Studies in Latin America, ya en 1943 argumentaba que "Brasil necesita más hospitales, centros comunitarios y vivienda barata en lugar de casinos y hoteles" (ibídem, 44).

Para Claudia Cabral, las críticas publicadas en Habitat "ganan un segundo impulso con la publicación del famoso "Report on Brazil" en las páginas de The Architectural Review en octubre de 1954" (2011:61). Con este reportaje, la revista inglesa refuerza las mencionadas acusaciones. La primera edición de Módulo, en 1955, presenta una respuesta directa al discurso crítico publicado en la revista inglesa, demostrando la inquietud de Niemeyer con la crítica internacional.

La producción textual de Niemeyer comenzó, ciertamente, con la creación de su revista. En 1955 aparece allí un cuerpo articulado de textos, en el que responde desde el comienzo -casi en tono de justificación- a las críticas contra su arquitectura. Durante el tiempo en que Módulo fue publicada, los textos fueron modificando su discurso, pasando de la defensa concreta de la producción del arquitecto hacia una apología amplia de una arquitectura moderna alineada con los principios del propio Niemeyer. Consecuentemente, el presente trabajo se enfoca en algunos de los temas más recurrentes de los textos que el carioca publicó en Módulo. 


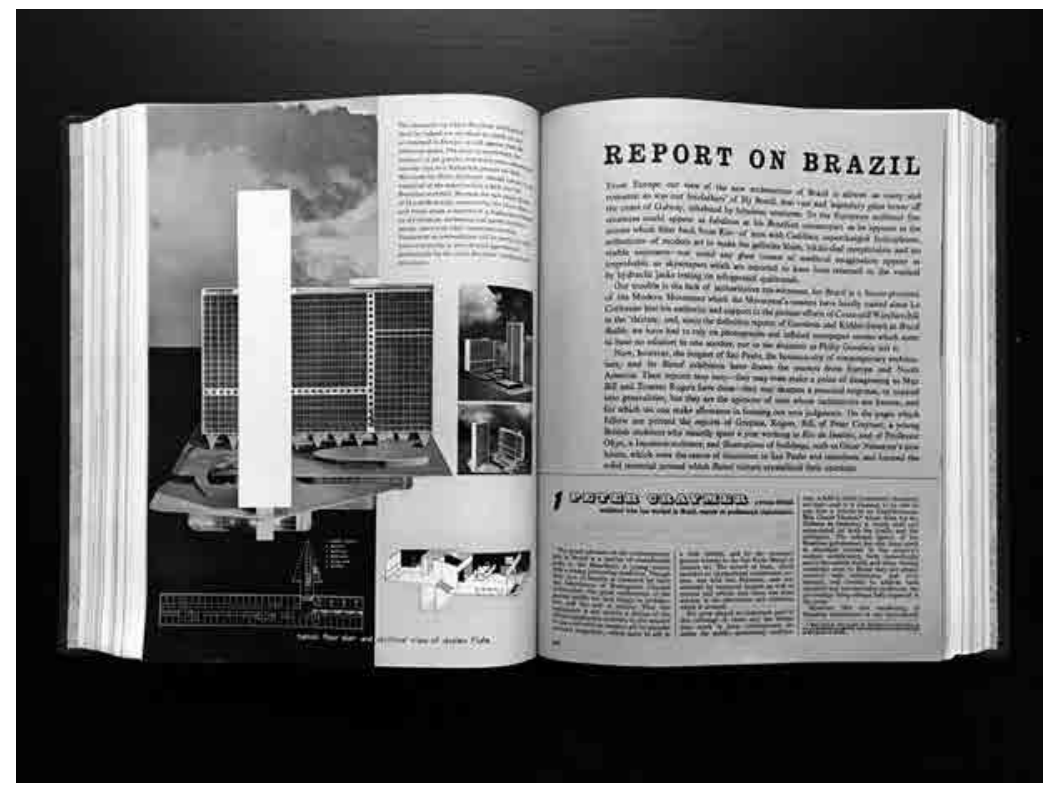

Figura 1 "Report on Brazil", publicado por Architectural Review en 1954. Fuente: Architectural Review, 1954, nº 694. pp. 234-235.

\section{MÉTODOS}

Este artículo es parte de una investigación realizada en el PROPAR - UFRGS en la que se comparó las revistas Módulo y Summa, lo cual demandó la lectura de los textos publicados en ambas publicaciones. La lectura de Módulo fue guiada por la hipótesis de Claudia Cabral acerca de la posición de defensa que Niemeyer toma al crear dicha plataforma. Al utilizar la analogía militar de la vanguardia, la autora posicionó la revista como defensora de un territorio ya dominado -"la escena brasilera"- a partir del cual el arquitecto podría avanzar "hacia otras posiciones en la escena internacional" (Cabral, 2011:66). En Brasil, los ataques directos al dominio de Niemeyer venían de la revista Habitat: "Toda la polémica entre Habitat y Módulo, aunque parezca entre paulistas y cariocas, tiene componentes importantes de internacionalización, tanto en la expectativa de ampliación de mercados profesionales, cuanto en el alcance del tema de fondo de la polémica, que es el debate sobre los límites del funcionalismo" (ídem).

La lectura de los textos de Niemeyer fue realizada de manera sistemática, colocándolos lado a lado con los proyectos vinculados a la Módulo en estas ediciones. En principio, se buscó un eje cronológico de organización de los textos, identificando la transformación del discurso del arquitecto a lo largo de los años. Sin embargo, esa tentativa se mostró errónea por la diversidad de los temas expuestos por Niemeyer que muchas veces se mezclaban en un mismo artículo. De esta manera, fue en los temas explorados en los textos que se apoyó el análisis del discurso, a ejemplo del trabajo hecho por Miguel Alves Pereira en Arquitectura, texto y contexto (1997), que estudia la obra escrita de Niemeyer de manera global.

\section{RESULTADOS}

Aunque toda la revista fue creada para defender un estilo arquitectónico determinado, ese discurso se fue adaptando de acuerdo a las circunstancias. Así, los textos de Niemeyer se fueron amoldando a la realidad profesional del autor. La creación de Módulo, en una década en la que la arquitectura brasilera era protagonista en la prensa internacional, ejemplifica esta toma de posición, cuando Niemeyer asume la función de portavoz de esta generación tan expuesta (Figura 1).

Si aceptamos la hipótesis según la cual Módulo fue creada sólo para defender la arquitectura de Niemeyer no sorprende que Niemeyer empezase a publicar su producción textual en una década en la que su recepción internacional comenzaba a cambiar de tono. Ante las primeras críticas recibidas, Niemeyer respondió con indiferencia, confiado en su "arquitectura como obra de arte que, como tal, solo subsiste cuando se revela espontánea y creadora" (1955a: 47). Asimismo, señala a Le Corbusier como figura inspiradora de este estilo, referente que "consiguió en quince años el prestigio mundial del que innegablemente hoy dispone" (ídem).

Pero dar respuesta a las críticas no fue la única función que Niemeyer ejerció a través de esta revista. También le preocupaba la baja calidad media de la arquitectura moderna brasilera y cómo esto podría perjudicar su legado, lo que le llevó a producir una serie de textos didácticos para combatir la "molestia de crecimiento" que ya había identificado en 1955.

Los últimos textos de Niemeyer publicados en Módulo en su mayoría entrevistas- lo muestran preocupado por su relevancia actual como profesional competente, y no 
apenas como una figura destinada a los libros de historia. Esta narrativa comienza de manera sutil pero acaba haciéndose explícita en la edición especial dedicada a los cincuenta años de arquitectura de Oscar Niemeyer.

A continuación, se presenta el análisis llevado a cabo a tres temas recurrentes en los textos de Niemeyer, que permite explicar el discurso del arquitecto durante las décadas en que Módulo fue publicada.

\section{DEFENSA ANTE LA CRÍTICA}

En 1955 Niemeyer se encontraba en una posición delicada, en la que al mismo tiempo era líder destacado y objetivo a batir, pues su obra era usada como ejemplo de la arquitectura brasilera, con los pros y los contras que eso conllevaba. Niemeyer, que hasta entonces decía que su obra debía defender su calidad por sí misma, sintió, por primera vez, la necesidad de explicarse. La tensión creció cuando Habitat publicó una entrevista en la que Max Bill condenaba la reacción de los arquitectos brasileros a las críticas que les había formulado. En tal sentido, indica Cabral:

\begin{abstract}
La polémica iniciada por Habitat en la escena brasilera gana un segundo impulso con la publicación del famoso 'Report on Brazil' en las páginas de The Architectural Review en octubre de 1954. El artículo incluía las opiniones de arquitectos extranjeros sobre la arquitectura moderna brasilera. [...]. Las consideraciones [...] sobre los caminos de la arquitectura moderna en Brasil, en mayor o menor medida, también contribuyeron a reforzar las acusaciones de futilidad, gratuidad y belleza intrascendente. (2011:61)
\end{abstract}

Ante este escenario, Niemeyer considera que el momento exige crear un vehículo propio de divulgación que afirmaría su lugar como pieza clave de una arquitectura moderna brasilera en busca de reconocimiento. Desde el primer número, Módulo se posicionó como una "plataforma para que Niemeyer mostrara sus propios proyectos de la manera que más le conviniera" (Ibídem: 56). Aquella portada inicial, con los pilares para el Parque de Ibirapuera (Figura 2), supuso el ejemplo emblemático de la citada postura. En cierto modo, estaba implícita una respuesta a la crítica de Max Bill a los pilotes del Edificio California, llamados por el suizo como "la última deformación de la forma libre y de la utilización fantasiosa de los pilotes" (1954:34). La respuesta figura en un texto sin autor, identificado como "Crítica a la Arquitectura Brasilera: MUY RICA -dicen". El tono es defensivo e intenta restar importancia a las críticas de los extranjeros:

El propio Max Bill -cuyas observaciones habían sido difundidas cuando estuvo aquí, a principios de 1954expone una monocórdica advertencia, no muy precisa y un tanto tímida, señalando que 'la arquitectura es un arte social'. A este respecto, el propio Gropius observa que 'los engaños de Niemeyer... no deben ser medidos por una regla suiza'. (1955:46)

El texto responde a cada uno de los argumentos del reportaje inglés, desde el más favorable al más antipático. El primero, de Peter Craymer, representaría, según Módulo, "el balance más razonable de la situación de la

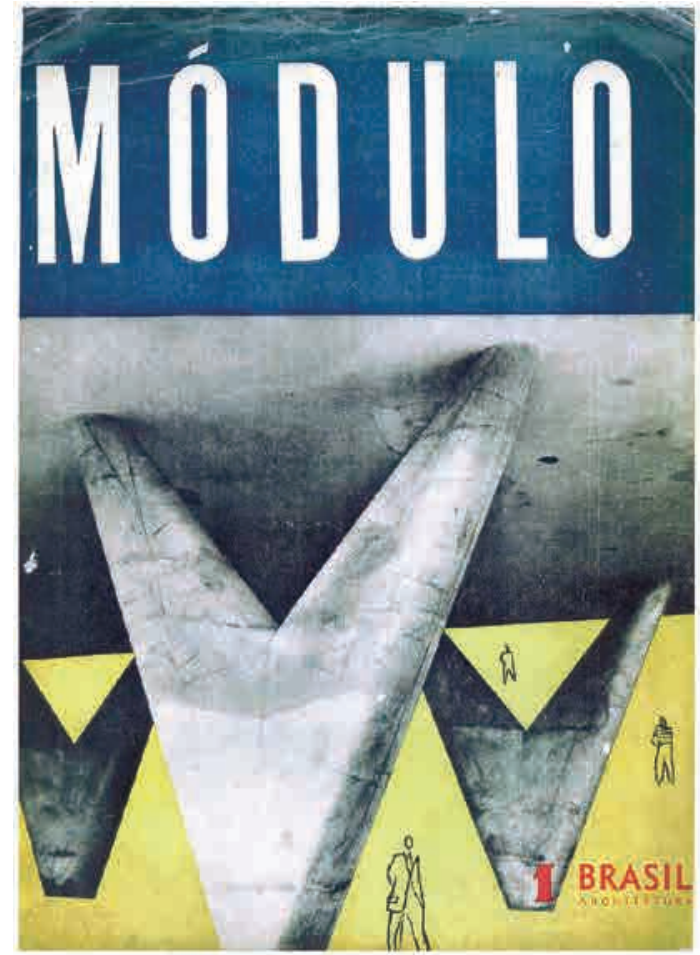

Figura 2 Portada de Módulo número 1. Fuente: Módulo, 1955 $n^{0} 1$.

arquitectura en Brasil" ("Crítica a la Arquitectura Brasilera", 1955:46), acertando en los comentarios sobre la industria de los materiales de construcción local y sobre cómo "las fallas o imperfecciones de nuestra arquitectura se deben, principalmente, a eso" (ídem).

El texto escrito por Gropius en "Report on Brazi"I tiene un tono demostrativo general y no se compromete a criticar edificios y arquitectos de forma específica. En general, la mayor preocupación de los autores en el citado artículo es la ausencia de planeamiento urbano. En cuanto a las obras específicas, elogian el edificio del Ministerio de Educación y Salud que consideran "un marco de la arquitectura moderna" (Gropius, 2003:153). De este edificio se dice que, aunque "bien construido, [...] su conservación parece precaria" (ídem). Ahora bien, en la revista Módulo se destaca la última parte del texto de Gropius: "Para finalizar, creo que se puede afirmar que los brasileros han desarrollado un tipo de arquitectura propia y ahora poseen numerosos arquitectos realmente talentosos, por delante de los demás. No creo que se trate de una moda pasajera sino de un movimiento vigoroso" (ibídem: 154)

Al responder a Max Bill, Módulo adopta una postura que roza la arrogancia e intenta diluir la importancia de la crítica. Desmenuzando los argumentos de Bill, Módulo indica que "después de una larga introducción amenazadora", el suizo apenas logra afirmar que la arquitectura 
brasilera "corre el riesgo de caer en un peligroso estado de academicismo antisocial" (BILL, 1954:34). Y como respuesta, se dice entonces que Bill es "esencialmente un ingeniero y matemático" que "resiente los vuelos imaginativos y creadores de los arquitectos brasileros" ("Crítica a la Arquitectura Brasilera", 1955:46).

El último texto analizado es el del italiano Ernesto Nathan Rogers, que planteó críticas formalistas a la arquitectura brasilera. Módulo cita sus críticas negativas, centradas en los "caprichos" provocados por el "personalismo de algunos de nuestros arquitectos -más específicamente, Oscar Niemeyer" (ídem). Como respuesta, la página siguiente publica un testimonio, firmado por Oscar Niemeyer bajo el título "Habla Oscar". En él, el arquitecto resta importancia a las críticas europeas y ni siquiera parece interesado en contestarlas. Su justificación es que considera "la Arquitectura como obra de arte que, como tal, solo subsiste cuando se revela espontánea y creadora" (Niemeyer, 1955a:47). En ese sentido, argumenta que: "Fue justamente dentro de ese espíritu de libertad y creación artística que nuestra Arquitectura consiguió en 15 años el prestigio mundial del que hoy disfruta" (ídem).

A los autores de las críticas, Niemeyer los considera -con excepción de Gropius- "hombres que no poseen, profesionalmente, las credenciales necesarias" (ídem). La conclusión es que nada de Rogers y Max Bill se conocería en Brasil, motivo que se desarrolla en un artículo publicado en la segunda edición de la revista, bajo el título "Crítica - Auto-Crítica". En este se presentan fotos de proyectos de Ernesto Rogers, acompañadas de un texto de tono casi vengativo:

\begin{abstract}
Módulo comentó, en su primer número, la actitud de algunos arquitectos extranjeros que nos han visitado y que asumen hacia la arquitectura brasilera una severa posición de crítica profesional. [...]
\end{abstract}

Módulo [...] tiene como objetivo dar a la crítica de dichos colegas su verdadera escala. Pues es de presumir que, a elaborar sus proyectos, ellos (sic) utilizan (sic) el sentido crítico con la misma dosis de severidad y discernimiento que aparentan tener. (1955:66)

En la edición 31, de diciembre de 1962, Módulo publicó un ensayo teórico de Niemeyer con el título "Contradicción en la Arquitectura". Se trata de un complemento al ensayo "Forma y Función en la Arquitectura", que había sido publicado en la edición 21 de la misma revista (1960). En este ensayo el arquitecto narra la evolución de la arquitectura moderna desde la época de "la máquina de habitar de Le Corbusier", en la que todo lo que no se adaptase al espíritu funcionalista era rechazado, hasta los años 60, cuando surge un "interés por la forma diferente, bella y creadora" (1962:17). Esta narrativa se ilustra con el relato de visitas que realizó durante un viaje a Europa:

Esta es la contradicción básica entre la Arquitectura Contemporánea y la bella, romántica arquitectura del pasado, contradicción que el advenimiento del hormigón armado estableció y que hasta hoy no ha sido superada. [...] Está presente en el propio acto de creación, en la actitud que el arquitecto asume frente a la obra, antes llena de lirismo y fantasía, hoy tímida y vacilante, contenida por las teorías que la crítica especializada intenta mantener. (ídem)
Módulo marcó, en definitiva, el intento de Niemeyer de "asumir las responsabilidades en la dirección del movimiento" (Miranda, 2008:14) a través de un conjunto de artículos de su propia autoría que, "tomados en conjunto, [...] pueden ser entendidos como un esfuerzo concreto de teorización" (Zein, 2012), cuyo objetivo fue defender su producción ante aquellos que, en palabras del arquitecto, "no [habían] sido [...] capaces de acompañarnos en las formas más libres que propusimos" (Niemeyer, 1978:30).

\section{DEFENSA DEL LEGADO}

La preocupación de Niemeyer por la influencia de su obra en la producción de los arquitectos brasileros estuvo presente desde la primera edición de Módulo. En el ya mencionado "Report on Brazil", Ernesto Rogers expone una reserva a los críticos de Niemeyer: "Si, de hecho, los innumerables imitadores compatriotas de Niemeyer son, muchas veces, un desastre, $y$ hay tontos que trasplantan sus semillas en territorios impropios, [...] no se puede atribuir culpa mayor al modelo [...] imputando la responsabilidad a Michelangelo cuando él es maltratado por discípulos de tercera categoría" (2003:167).

Al contestar el reportaje de la revista inglesa, Módulo insiste en apuntar un error común de la crítica, que consiste en "juzgar un artista por sus imitadores" ("Crítica a la Arquitectura Brasilera", 1955a:46). Es la primera vez que aparece una mención a los seguidores de Niemeyer como posibles responsables de las exageraciones de la arquitectura brasilera de aquella década.

En la tercera edición de la revista Módulo, aún en 1955 Niemeyer publicó el texto "Problemas actuales de la arquitectura brasilera" (Figura 3), en que atribuía a la popularización rápida de la arquitectura moderna en Brasil la pérdida de calidad de algunas obras recientes, que sufrieron lo que él llamó "molestias de crecimiento". Niemeyer inicia su texto reconociendo la insatisfacción de algunos arquitectos con los rumbos de la arquitectura brasilera. Según él, las críticas se dividían en dos temas: aquellos que defendían el uso de técnicas tradicionales de construcción y los que se preocupaban por la baja calidad de las obras contemporáneas. Niemeyer reconoce el bajo nivel arquitectónico de algunas de las obras recientes, lo que considera un problema grave pero previsible, dado que la arquitectura moderna se había vuelto tan popular en Brasil que acabó convirtiéndose en la arquitectura corriente del país:

Es natural y comprensible que esa masa enorme de construcciones, extendiéndose por todo el país, no pudiera mantener el mismo nivel técnico, principalmente considerando el éxito que las buenas obras alcanzaban y su sentido nuevo y creador que todos -pudiesen o no deseaban acompañar. [...]

Todo esto, entretanto, es una especie de "molestia de crecimiento", que debemos mirar sin sorpresa, comprensiblemente, buscando, mediante una pertinaz campaña didáctica combatir y eliminar. (Niemeyer, 1955b:66) 


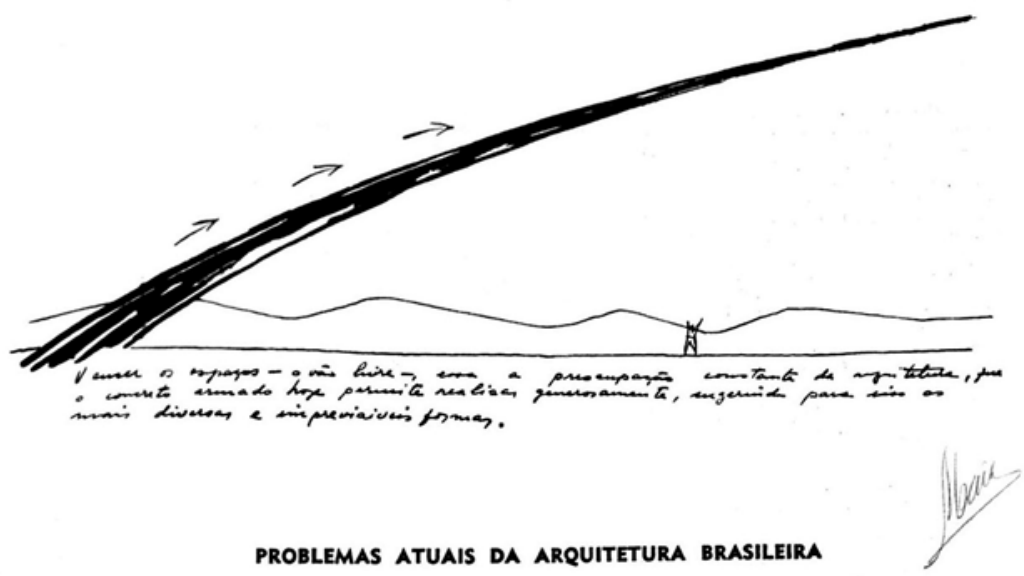

OSCAR NIEMEYER

Figura 3 "Problemas Atuais da Arquitetura Brasileira". Fuente: Módulo, 1955, n³, p.19.

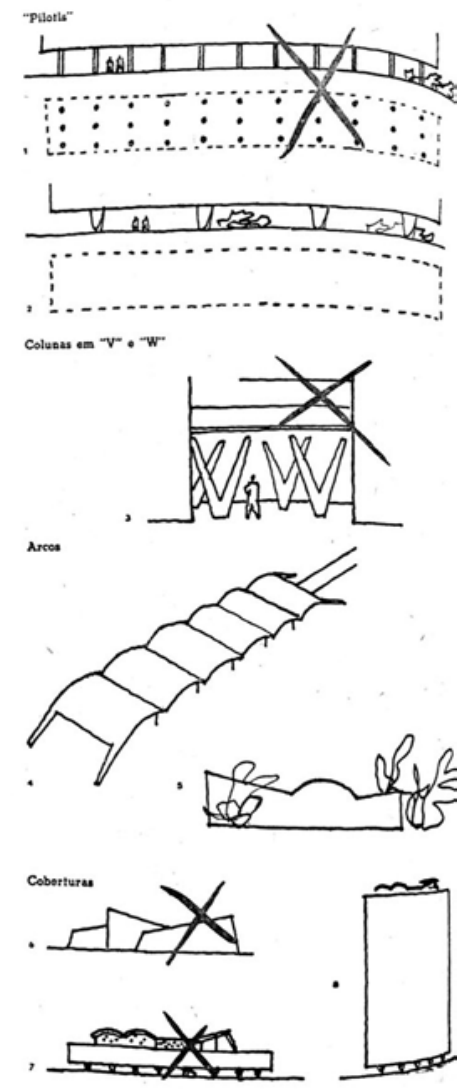

Figura 4 Dibujos didácticos de Niemeyer Fuente: Módulo, 1957, nº 7, p. 6. 
Los textos de Niemeyer publicados en Módulo a partir de la edición 40, en 1975 (diez años después de ser cerrada por la dictadura militar), intensifican la preocupación por las obras derivadas de su trabajo. Estos artículos, de carácter didáctico (Figura 4), constituyen manuales de buena arquitectura, en los que se denuncia los excesos cometidos por los contemporáneos como contraejemplos de los edificios de Niemeyer.

Entre 1978 y 1980 Niemeyer publicó una serie de textos que formaban un conjunto coherente de lecciones de arquitectura. Al contrario de los demás artículos publicados por la revista a lo largo de los años, estos componen una serie planeada a priori para formar un todo inteligible. Todos los títulos son presentados con el prefijo "P.A." y el número, indicando ser parte de una obra mayor. En 1986, la editorial Vozes los reunió en un libro llamado Cómo se hace Arquitectura (Figura 5) para el cual Niemeyer escribió la siguiente presentación: "Son los artículos publicados en la revista Módulo, lecciones de arquitectura, secretos del arte de proyectar. Dado que no figuran en los libros y son útiles y esclarecedores, accedí a reunirlos en este pequeño libro. Una contribución a los arquitectos más jóvenes de mi país" (1986: 6).

En dichos textos, Niemeyer coloca la libertad formal de su obra en continuidad con la evolución de la forma arquitectónica. La búsqueda por vencer el vano libre va desde las "vigas y dinteles de piedra y madera, pasa por las vigas de madera y hierro y, finalmente, [acaba en] el hormigón armado" (Niemeyer, 1980:94).

No faltan comparaciones entre su producción y algunos ejemplos canónicos de la historia de la arquitectura. Niemeyer cita los puentes de Freyssinet y la obra de los "viejos maestros de la arquitectura" para ver cómo "Palladio perseguía la levedad arquitectónica" (1986: 56). El objetivo de estas referencias es ilustrar la preferencia, en Brasilia, por las columnas de punta fina.
El tono de estos textos muestra a un Niemeyer mucho más preocupado por su legado que por la validación de su obra que, en su opinión, ya era relevante y bastaba para servir de lección a los más jóvenes.

Así también, en estos textos, Niemeyer se refiere a los proyectos realizados por él para ilustrar lecciones de otros maestros, como Zevi o el poeta Reiner Maria Rilke, por ejemplo. El primero de ellos, perteneciente a la serie "Espacio Arquitectónico" y publicado en la edición 50 de 1978, es el único que cita la obra de otros arquitectos contemporáneos: Le Corbusier es destacado como precursor en la articulación de los volúmenes internos en los edificios, y la terminal de Saarinen en Nueva York se comenta brevemente en la presentación del auditorio de la Bolsa de Trabajo de Bobigny.

Aunque en sus primeros años Módulo estuvo dedicada a la reacción a la crítica internacional, a partir de 1975 adoptó maniobras al mismo tiempo más agresivas y sutiles en el campo de batalla editorial. En efecto, los textos publicados a finales de la década de 1970 no responden directamente a ninguna crítica sino que son fruto de la preocupación del arquitecto por su legado arquitectónico. En ellos se defiende la arquitectura de Niemeyer desde una perspectiva que ya la considera una obra canónica, poniéndola lado a lado con la de los arquitectos cuya relevancia era incuestionable y posicionando definitivamente al brasilero entre los grandes maestros del oficio.

\section{DEFENSA DE LA RELEVANCIA}

Después de la publicación de la serie "Problemas de la Arquitectura", los textos de Niemeyer se limitan a comentarios que acompañan sus proyectos, normalmen-
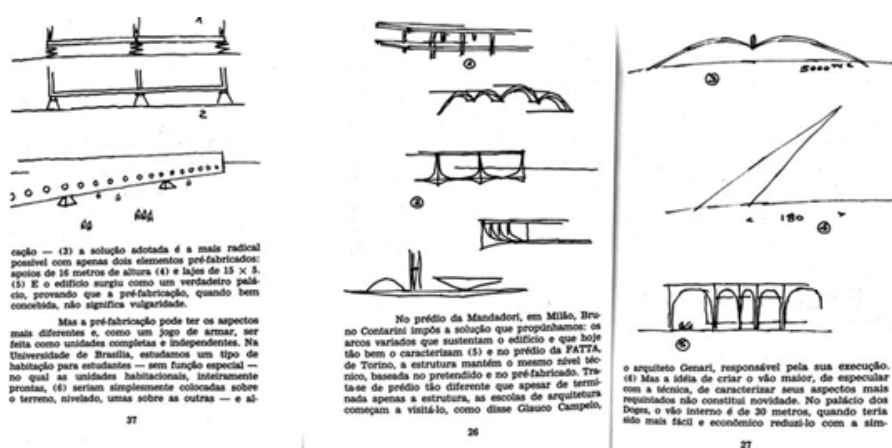

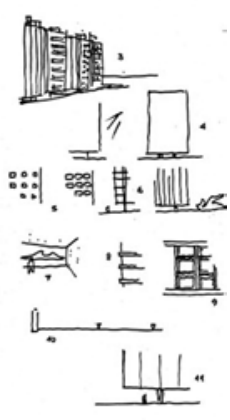


te publicados junto a los planos, y escritos a mano en la caligrafía original del autor (Figura 6). Durante la última década de la revista, los textos de carácter teórico fueron paulatinamente sustituidos por relatos biográficos y anécdotas que relataban las mismas historias.

Los últimos textos de Niemeyer publicados en Módulo -en su mayoría entrevistas- lo muestran preocupado por su relevancia actual como profesional competente, y por no ser sólo una figura destinada a los libros de historia, sin una producción contemporánea. Un ejemplo de esta narrativa es la edición número 97, de 1987, un número especial en homenaje al centenario de Le Corbusier que inicia con una carta escrita por el suizo en su última visita al Brasil, en 1962. En esta carta, con tono de despedida de Brasil, Le Corbusier resalta al país como "Uno de esos lugares acogedores que gusto de llamar amigo" (Le Corbusier, 1987:1): "Brasilia está construida, vi la ciudad recién nacida. Es magnifica su invención, su coraje, su optimismo. Le habla al corazón. Es obra de mis dos grandes amigos (a través de los años), compañeros de lucha, Lucio Costa, Oscar Niemeyer. En el mundo moderno, Brasilia es única" (ídem).

Uno de los artículos publicados en esta edición, firmado por la redacción de la revista, termina con las palabras de Niemeyer, que parece querer resaltar su propia arquitectura más que elogiar la obra de su maestro. En ese sentido, cita la resistencia de Le Corbusier a las líneas curvas: "el orden de las plantas de dentro hacia afuera, el menos es más, la pureza de la arquitectura, y hasta la máquina de habitar que luego olvidó cuando cubrió Ronchamp de rectas y curvas, consciente de que las belleza bastaba para justificarlas" ("Arquitecto de nacimiento", 1987:19). Y prosigue hablando de la obvia influencia del maestro de la arquitectura moderna en su generación, pero también de aquella que los brasileros habían tenido en la obra corbusieriana: "Pero fue bueno leer en el libro de memorias de Ozenfant aquella frase significativa: 'Le Corbusier a partir de cierta fecha pasó a despreciar el ángulo recto, atraído por una arquitectura que venía de fuera con mucho talento'" (ibídem, 18).

Poco tiempo después, todavía en el mismo año, Módulo publica otra edición conmemorativa, dedicada a los cincuenta años de actuación profesional de Oscar Niemeyer. Se trata de una retrospectiva de su obra, con un listado de todos los proyectos realizados por el arquitecto, además de los testimonios de algunos amigos ilustres, una entrevista y un pasaje del libro de memorias que Niemeyer estaba escribiendo a finales de los 90 .

\section{CONCLUSIONES}

Los tres temas recurrentes en los textos de Niemeyer en Módulo reflejan un cambio en su percepción del escenario arquitectónico. Si en los años 50 necesitaba defender la posición ya conquistada y hegemónica, a inicios de los 90 intentó mostrar que aún tenía relevancia profesional. El modo en que Módulo articula esta maniobra es instalándolo como símbolo de la Arquitectura Moderna brasilera y, al mismo tiempo, como "enlace necesario entre nuestra historia y nuestro futuro" (Companheiros de
Módulo, 1987:19); con lo cual se buscaba, probablemente, evitar el riesgo de que Niemeyer fuera considerado sólo una figura histórica obsoleta.

En los primero textos, publicados en un período en el cual Niemeyer gozaba de un protagonismo inédito en la arquitectura moderna, el arquitecto intentó responder a una crítica internacional que, al mismo tiempo, resaltaba y cuestionaba duramente su obra. En un segundo momento, sus artículos tienen una intención teórica y didáctica, reflejada en la serie "Problemas de la Arquitectura", que posteriormente fue editada en formato de libro y hoy constituye evidente referencia para los jóvenes arquitectos. Al aproximarse los años 90 , su lenguaje cambia nuevamente, cuando el arquitecto deja de explicar su obra para adoptar un discurso poco descriptivo cargado de referencias externas a la arquitectura.

Los textos de Niemeyer en Módulo pueden ser entendidos, en suma, no sólo como un intento de responder a las críticas a su arquitectura, sino también de orientar a una nueva generación de arquitectos y, "mediante de una pertinaz campaña didáctica" (Niemeyer, 1955b:66), combatir y eliminar cualquier síntoma de aquella "molestia" que, desde su punto de vista, estaba sufriendo la arquitectura moderna brasilera después de la superexposición de los años 50. Gracias a todo ello, afirmó su posición como líder y figura máxima de un movimiento.
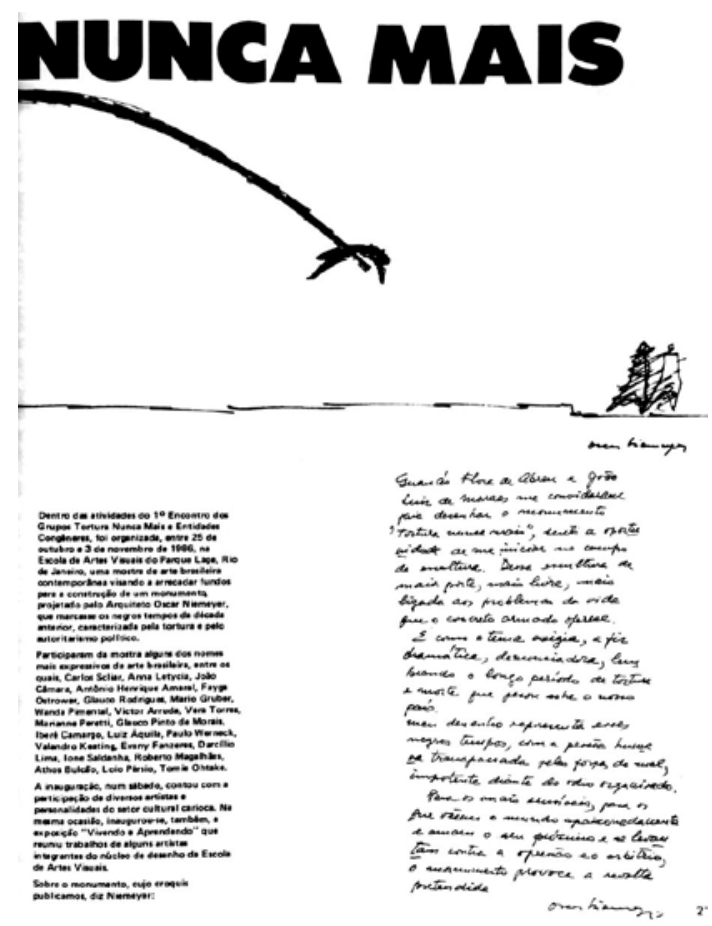

Figura 6 Memorial descriptivo del monumento "Tortura Nunca Mais". Fuente: Módulo, 1986, n 92, p. 21. 


\section{REFERENCIAS BIBLIOGRÁFICAS}

Arquiteto por nascimento. Módulo, 1987, n 96, p. 18

BILL, Max. O arquiteto, a arquitetura, a sociedade. Habitat, 1954, no 14, pp. 34-35.

CABRAL, Claudia. La revista como escudo: Módulo y Oscar Niemeyer. En: TORRENT, Horacio (ed.). Revistas de Arquitectura: Representaciones urbanas y paradigmas disciplinares. Santiago de Chile: T6 Ediciones, 2011, pp. 49-70.

COMAS, Carlos Eduardo. La revista como lanza: Habitat y Lina Bo Bardi. En: TORRENT, Horacio (ed.). Revistas de Arquitectura: Representaciones urbanas y paradigmas disciplinares. Santiago de Chile: T6 Ediciones, 2011, pp. 33-47.

COMPANHEIROS DE MÓDULO. Oscar Niemeyer 50 anos de arquitetura. Módulo, 1987, n 97, p. 19.

Crítica - Auto Crítica. Módulo, 1955, n² 2, p. 66.

Criticada a arquitetura brasileira: RICA DEMAIS - dizem. Módulo, 1955, n 1, p. 46.

GROPIUS, Walter. Um Vigoroso Movimento (1954). En: XAVIER, Alberto (ed.). Depoimento de uma geração. São Paulo: Cosac Naify, 2003, pp. 153-154.

LE CORBUSIER. Carta. Módulo, 1987, n 95, p. 1.

MIRANDA, Clara Luiza. A Crítica nas revistas de arquitetura dos anos 50. En: SEGRE, R., V Seminário de História da Cidade e do Urbanismo. Campinas: Universidade Católica de Campinas, 2008.

NIEMEYER, Oscar. Fala Oscar. Módulo, 1955a, n 1, p. 47.

NIEMEYER, Oscar. Problemas Atuais da Arquitetura Brasileira. Módulo, 1955b, n³, p. 19.

NIEMEYER, Oscar. Contradição na Arquitetura. Módulo, 1962, no 31, p. 17.

NIEMEYER, Oscar. A forma na arquitetura. Rio de Janeiro: Avenir editora, 1978.

NIEMEYER, Oscar. O problema estrutural. Módulo, 1980, $n^{\circ} 57$, p. 94.

NIEMEYER, Oscar. Como se faz Arquitetura. Rio de Janeiro: Vozes, 1986.

PEREIRA, Miguel Alves. Arquitetura, texto e contexto: 0 discurso de Oscar Niemeyer. Brasília: Editora Universidade de Brasília, 1997.

Report on Brazil. Architectural Review, 1954, n 694. pp. 234-250.

ROGERS, Ernesto Nathan. Pretextos para uma crítica não formalista (1954). En: XAVIER, Alberto (ed.). Depoimento de uma geração. São Paulo: Cosac Naify, 2003, pp. 166169.

STUCHI, Fabiana Terenzi. Revista Habitat: um olhar moderno sobre os anos 50 em São Paulo. Dissertação, FAUUSP, USP, São Paulo, 2007.

ZEIN, Ruth Verde. Da crítica alheia à teoria própria [en línea]. Arquitextos, 2012, no 151.04. [Consultado 19 diciembre 2016]. Disponible en: http://www.vitruvius. com.br/revistas/read/arquitextos/13.151/4608 